\title{
REPRESENTAÇÕES SOCIAIS DA LEITURA: núcleo central e periferia dessas representações entre professores
}

\author{
SOCIAL REPRESENTATIONS OF READING: central and peripheral \\ elements of these representations among teachers
}

\author{
Elsa Maria M. Pessoa Pullin* \\ Leila Cleuri Pryjma ${ }^{* *}$
}

\begin{abstract}
Resumo
Este artigo objetiva caracterizar a estrutura das representações sociais de leitura de professores que atuam no Ensino Fundamental da rede municipal de uma cidade do interior do Paraná. Um teste de associação livre de palavras foi utilizado para o levantamento dos dados. Das 322 palavras diferentes registradas, processadas pelo software EVOC, os elementos "conhecer", "informar" e "essencial" parecem ser os constituintes do provável núcleo. Para esse grupo de professores, a leitura é essencial e necessária para a apropriação de conhecimentos. Implicações desses sentidos acerca da leitura e sugestões são apresentadas no decorrer do texto.
\end{abstract}

Palavras-chave: Leitura. Representações Sociais. Professores.

\begin{abstract}
This paper aims to characterize the structure of the social representations of reading held by first and middle-school teachers from city public schools in a city in the interior of Paraná, Brazil. A free word association test was used for data collection. Of the 322 different words recorded, which were processed by the EVOC software, the elements "know", "inform" and "essential" seem to be central. For this group of teachers, reading is essential and necessary for knowledge acquisition. Implications of these meanings of reading and suggestions are presented throughout the paper.
\end{abstract}

Keywords: Reading. Social Representations. Teachers.

\begin{abstract}
Enquanto grupo socioprofissional, construímos nossas próprias representações e, em função delas, construímos nossas práticas e as impomos aos alunos, na suposição de que sabemoso que é bom para eles.
\end{abstract}

(ALVES-MAZZOTTI, 1994, p. 71)

Qualquer mudança que se queira alcançar pela educação escolar "exige que se compreendam os processos simbólicos que ocorrem na interação educativa, e esta não ocorre num vazio social." (ALVES-MAZZOTTI, 1994, p. 60). Nesse tipo de interação, a linguagem é frequentemente utilizada para viabilizar o ensino. Como em quaisquer outras situações, para que a interação educativa aconteça efetivamente, para os alunos aprenderem o que o professor ensina, precisam compartilhar sentidos

\footnotetext{
"Professora associada na Universidade Estadual de Londrina. E-mail: pullin@uel.br

** Mestre em Educação pela Universidade Estadual de Londrina. E-mail: profleilapryjma@gmail.com
}

próximos ou similares. Os sentidos ou interpretações atribuídos à produção do outro são duplamente determinados. Decorrem tanto do pertencimento individual a um grupo sociocultural, o qual ultrapassa a situação da aula, como dos "[...] enquadres institucionais, [...] relações de poder e hierarquia nas instituições e [...] papéis sociais aí assumidos" (ROJO, 2000, p. 201). Como assinala Soares (2005, p. 548): "Utilizar as palavras duma língua significa mergulhar no saber simbólico histórico e cultural, mas significa também marcar uma tomada de posição relativamente ao que se diz".

Por concordarmos com essa autora quanto ao fato de que "A verbalização de ideias e pensamentos implica o suporte de uma língua: e 'as palavras duma língua natural incluem um imprint de significados de natureza cultural, que são uma espécie de 'depósito' que as representações sociais deixam no léxico'” (SOARES, 2005, p. 548, destaque da autora), decidimos investigar as representações sociais (RS) de leitura de professores que atuam nas séries iniciais do Ensino Fundamental, tendo por premissa que são os universos simbólicos que regulam as ações e as práticas individuais. 
As representações funcionam como uma "Grade de interpretação e de decodificação da realidade, [...] produzem a antecipação dos atos e dos comportamentos (seus e dos outros), a interpretação da situação num sentido preestabelecido, graças a um sistema de categorização coerente e estável" (ABRIC, 2001a, p. 168). Por sua vez, Moscovici evidencia: "Os comportamentos individuais ou de grupo são diretamente determinados pelas representações elaboradas em e sobre a situação e o conjunto de elementos que a constituem." $E$ as "nossas representações internas, que herdamos da sociedade, ou que nós fabricamos, podem mudar nossa atitude em relação a algo fora de nós mesmos". (MOSCOVICI, 2010, p. 102).

Assim sendo, este trabalho inscrito teórica e metodologicamente no campo da Teoria das Representações Sociais (TRS) busca identificar o universo simbólico que abriga as RS de leitura de professores que atuam na rede municipal de ensino de uma cidade de médio porte localizada na região norte do estado do Paraná.

A opção teórica de quem investiga regula ou deve regular sua perspectiva ontológica e epistemológica quando se acerca do objeto que decide investigar, assim como os métodos de recolha e de análise dos dados. No campo das RS, alguns pressupostos e decisões devem ser enunciados, visto que, por princípio, a TRS não admite como equivalentes o fenômeno e o objeto de investigação.

Nesse sentido, um dos pioneiros no Brasil, em investigações no campo das RS, adverte: "Na construção do objeto de pesquisa em representações precisamos levar em conta simultaneamente 0 sujeito e o objeto da representação que queremos estudar." (SÁ, 1998, p. 24). Após demonstrar a nãoequivalência entre um fenômeno da representação social e o objeto a ser investigado (porque o fenômeno é mais amplo do que o objeto da pesquisa), esse autor explica que o processo de construção do objeto de pesquisa exige uma série de tomadas de decisão por parte do pesquisador, desde aquelas iniciais relativas à escolha do fenômeno, que deve ser relevante, às de natureza teórica e metodológica.

Em vista disso, a estrutura restante deste trabalho foi organizada em tópicos. Inicialmente, são delineados os aportes gerais teóricos e metodológicos que orientaram a proposição do estudo, e os argumentos que situam a posição que assumimos sobre o fenômeno que selecionamos para construir o objeto da investigação realizada, isto é, as representações sociais de leitura para um grupo de professores. A descrição do método e a análise dos resultados obtidos antecedem as considerações que fecham, sem os encerrar, os propósitos deste estudo.

\section{Introdução}

Tomando-se por pressupostos a afirmação "Nas culturas letradas, sem ler e sem escrever, não se pode estudar, buscar conhecer, apreender a substantividade do objeto, reconhecer criticamente a razão de ser do objeto", de Paulo Freire (2001, p. 87); as palavras de Alves-Mazzotti (1994) utilizadas como epígrafe deste texto; e as ponderações de Gimeno Sacristán, quando diz que o inimigo da leitura não reside na cultura audiovisual e na extensão de novas tecnologias, como algumas pessoas temem, "mas nas desafortunadas práticas de leitura dominantes a que submetemos os nossos alunos durante a escolaridade" (GIMENO SACRISTÁN, 2008 , p. 87), somos instigados a perguntar: no Brasil, especialmente em escolas, faculta-se aos alunos aprenderem a realizar uma leitura como a defendida por Paulo Freire? Como professores, quais são as RS de leitura que regulam nossas práticas educativas, por supormos serem as melhores que sabemos (ALVES-MAZZOTTI, 1994), mas nem sempre as favoráveis (GIMENO SÁCRISTAN, 2008) para incentivar os alunos a ler? Em que medida esses modos de agir contribuem para que os alunos apresentem baixos desempenhos em provas nacionais (SAEB, Prova Brasil, ENEM) e internacionais (PISA) que têm como meta avaliar seu desempenho em leitura? Este trabalho não tem a pretensão de realizar macroanálises, como exigem as respostas possíveis à primeira e à última questão, mas apenas contribuir, mesmo que parcialmente, para responder à outra questão, por visar, unicamente, à configuração das RS de leitura construídas por um grupo de professores do ensino fundamental que atua em um município paranaense.

\section{Teoria das Representações Sociais (TRS)}

Não sem razão, Jodelet (2008) se apropriou do significado que Tarde deu ao termo beautiful para intitular um de seus textos. Assim o fez, por considerar o livro Psychoanalysis, its image and its public como seminal, e por essa produção de Moscovici ter levado à descoberta de mais ideias a respeito do tema, podendo ser considerada uma invenção fecunda para as produções que a seguiram. Argumenta a autora: "A obra de Moscovici nunca foi um projeto para futura repetição imitativa, como frequentemente acontece na Psicologia. Essa obra foi um impulso para abrir novos caminhos de descoberta" (JODELET, 2008, p. 411).

Para a compreensão dos fatos da Educação, Gilly (2001, p. 321) assinala a importância da noção de RS, com o argumento: "[...] orienta a atenção para 
o papel de conjuntos organizados de significações sociais no processo educativo", auxiliando a compreender fenômenos macroscópicos, como "as relações entre a pertença a um determinado grupo social e as atitudes e comportamentos diante da escola [..., como também] os relativos à comunicação pedagógica na turma e à construção de saberes." (GILLY, 2001, p. 322). No Brasil, autores como Alves-Mazzoti (1994, 2007, 2011) e Madeira (2003), por exemplo, vêm demonstrando a importância da TRS para a Educação.

Apartir de 1980, com a fundação daAssociação Brasileira de Psicologia Social (ABRAPSO) verificase a preocupação dos pesquisadores em tratarem os fenômenos sociais a partir das abordagens da TRS. A análise da produção de livros brasileiros nesse campo permite constatar que, a partir das duas últimas décadas, começaram a surgir obras como a organizada por Mary Jane Spink, em 1993, e a coletânea organizada por Pedrinho Guareschi e Sandra Jovechelovitch, no ano seguinte. A produção acadêmica em periódicos de circulação nacional foi iniciada com a publicação, em 1991, do artigo Representações sociais: pressupostos e implicações, de Margot Campos Madeira, seguido, em 1994, pelo artigo intitulado Representações sociais: aspectos teóricos e aplicações à educação, de Alda J. Alves-Mazzotti.

Pode-se dizer, ainda, que a fundação, em 2006, do Centro Internacional de Estudos em Representações Sociais e Subjetividade - Educação (CIERS-ed), bem como do Centro Internacional de Pesquisa em Representação e Psicologia Social "Serge Moscovici" (CIRPS), sediado na Universidade de Brasília, desde 2010, vem estimulando a investigação e divulgação da TRS no Brasil.

Uma consulta ao portal do SciELO, utilizando como buscador o verbete representações sociais, deu conta de que até 23/2/2011, 155 artigos estavam disponíveis para consulta, produzidos por pesquisadores de distintas áreas de conhecimento. A análise da produção acadêmica de dissertações e teses, especificamente no campo da Educação, como a realizada por Menin, Shimizu e Lima (2009), e dos 138 trabalhos divulgados em congressos, no período de 2000 a 2003 (MENIN; SHIMIZU, 2005), demonstram que essa teoria tem dado suporte aos pesquisadores para compreenderem seus objetos de estudo no campo da Educação.

Neste estudo adotamos a abordagem estrutural proposta por Jean-Claude Abric, como aporte teórico e metodológico, no campo da TRS. Assim o fizemos, porque essa abordagem assenta-se na premissa de que as representações sociais estão organizadas em torno de um núcleo, interpretado como seu elemento fundante, o qual determina a sig- nificação e organização interna de uma dada representação social. Ademais, essa abordagem propicia elementos úteis para a compreensão e explicação dos processos de aquisição e transformação das representações sociais. No caso deste estudo pretendemos apenas identificar os elementos principais que configuram as representações sociais acerca de leitura nesse grupo de professores, para que essas informações possam fundamentar, posteriormente, a proposição de ações de formação mais efetivas a esse grupo de professores.

Os trabalhos desenvolvidos sob essa abordagem têm retomado a noção de representação social apresentada por Serge Moscovici em 1961, por entender-se que a "identificação da 'visão de mundo' que os indivíduos ou os grupos têm e utilizam para agir e tomar posição, é indispensável para compreender a dinâmica das interações sociais e clarificar os determinantes das práticas sociais." (ABRIC, 2000 , p. 27 , destaque do autor).

A seguir apresentamos com mais detalhes as proposições de Abric sobre alguns dos aspectos caracterizadores dessa abordagem, hoje conhecida como Teoria do Núcleo Central e Periférico.

Essa teoria foi proposta pela primeira vez em 1976, quando Abric defendeu em sua tese de Doctorat d'État a seguinte proposição: "Aorganização de uma representação apresenta uma característica específica, a de ser organizada em torno de um núcleo central, constituindo-se em um ou mais elementos, que dão significado à representação." (ABRIC, 1976 apud ABRIC, 2000, p. 31).

Levando em consideração que toda a realidade "é representada, quer dizer, reapropriada pelo indivíduo ou pelo grupo, reconstruída no seu sistema cognitivo, integrada no seu sistema de valores, dependente de sua história e do contexto social e ideológico que o cerca" (ABRIC, 2000, p. 27), transcrevemos alguns trechos que mostram como Abric caracteriza uma RS: "A representação não é um simples reflexo da realidade, ela é uma organização significante." (ABRIC, 2000, p. 28). Para ele, a RS é uma forma global e unitária tanto de um objeto como de um sujeito. Por assim compreendê-la, o referido autor destaca que a representação social permite ao indivíduo integrar as características objetivas do objeto, das suas experiências anteriores e do seu sistema de atitudes e de normas. Isso porque a RS reestrutura a realidade e possibilita a cada pessoa "dar sentido às suas condutas e compreender a realidade através de seu próprio sistema de referências; permitindo assim ao indivíduo se adaptar e encontrar um lugar nesta realidade." (ABRIC, 2000, p. 28).

Além dessas funções, qualquer RS permite ao indivíduo se perceber como tal e se sentir como membro de um grupo, bem como serve de "guia para 
a ação [...] orienta as ações e as relações sociais. Ela é um sistema de pré-codificação da realidade porque determina um conjunto de antecipações e expectativas." (ABRIC, 2000, p. 28).

Em 1994, Jean-Claude Abric retoma alguns trechos do texto da tese que defendeu em 1976, para esclarecer o que entende por núcleo central das RS, dos quais transcrevemos:

A organização de uma representação apresenta uma característica particular, específica: os elementos da representação não são apenas hierarquizados, mas além disso toda representação é organizada em torno de um núcleo central, constituído de um ou de alguns elementos que dão à representação o seu significado (ABRIC, 1994, p. 19).

Em suas obras, Abric (1993, 1994, 2000, 2001) diferencia dois núcleos/sistemas constituintes das representações sociais: o periférico, que abriga os elementos passíveis de mudança mais rápida, os quais são, por isso, considerados bem mais flexíveis do que aqueles que constituem o outro núcleo - o núcleo central da representação. Ambos contribuem para o indivíduo interpretar a realidade e determinam seus comportamentos e práticas.

As sumarizações apresentadas em quadros por Abric (2000, p. 31-34) permitem a visualização esquemática das características e funções do sistema central e do sistema periférico das RS, identificadas a partir dos resultados de muitos anos de pesquisa na abordagem estrutural. Foram as análises desses resultados que deram suporte para a conclusão de que qualquer "representação é organizada em torno de um núcleo central" (ABRIC, 1994, p. 21), cujos elementos dão significado à representação. Este núcleo desempenha duas funções principais: a função generadora e a função organizadora. Enquanto a primeira função possibilita que "se crie, ou se transforme o significado dos outros elementos constitutivos da representação, [...] e que outros elementos ganhem um sentido, um valor", a função organizadora "determina a natureza dos elos, unindo entre si os elementos da representação" (ABRIC, 2000 , p. 31). Conforme Abric (2000, p. 31), o núcleo central "é o elemento unificador e estabilizador da representação." Por sua vez, três são as funções dos elementos periféricos de quaisquer representações sociais: concretização, regulação e defesa (ABRIC, 2000).

Abric $(1994,2000)$ salienta a importância e desdobramentos dos estudos e do trabalho de Claude Flament, porquanto eles "constituem um avanço importante na análise do papel deste sistema periférico" (ABRIC, 1994, p. 26), ao proporem os elementos periféricos como esquemas, organizados pelo núcleo central. Ao assim fazê-lo, Flament (1989 apud ABRIC, 2000, p. 32) entende que esses esquemas garantem "de modo instantâneo o funcionamento da representação como guia de leitura de uma situação". Apoiando-se na proposição de Flament quanto à importância desses esquemas para o funcionamento das representações, Abric $(1994,2000)$ resgata as características propostas por esse autor, quais sejam a de serem prescritoras de comportamentos, moduladoras personalizadas das representações e das condutas a elas associadas, e protetoras do núcleo. No entanto, Abric acrescenta que, além de os elementos periféricos serem prescritores de comportamentos, também são responsáveis pelas

tomadas de posição do sujeito. Eles indicam de fato, o que é normal de se fazer ou de se dizer em uma dada situação. Eles possibilitam, assim, a orientação das ações e reações dos sujeitos de modo instantâneo, sem a necessidade de recurso aos significados centrais (ABRIC, 2000, p. 32).

Em suma, segundo a proposição de JeanClaude Abric, as RS comportam um duplo sistema, um central e um periférico, com características e funções diferentes: o núcleo central congrega os elementos que apresentam maior resistência à mudança, que perduram por mais tempo, ao passo que os elementos que constituem o núcleo periférico possibilitam a interface entre a representação elaborada e os efeitos das experiências individuais. Por isso respondem duplamente pelas possibilidades de maior variação e de menor resistência a mudanças.

No Brasil, diversas pesquisas têm utilizado a proposição de Jean-Claude Abric para sustentar a investigação de RS de diferentes fenômenos, como as compiladas nas obras de Moreira e Oliveira (2000), de Santos e Almeida (2005), de Guareschi e Jovchelovitch (2008), por exemplo, além daquelas publicadas em revistas científicas, disponíveis nos periódicos do portal ScieELO-Brasil, e das divulgadas em eventos nacionais - como os organizados em Educação pela Associação Nacional de PósGraduação e Pesquisa em Educação (ANPEd), e em Psicologia, pela Associação Nacional de Pesquisa e Pós-Graduação em Psicologia (ANPPEP) - e em eventos regionais e internacionais, como os editados pela Associação Brasileira de Psicologia Social (ABRAPSO).

Como adverte Sá (1994), "Um aspecto muito importante da teoria das representações sociais é o de atribuição necessária de uma gênese social aos fenômenos de que ela se ocupa" (SÁ, 1994, p. 40). A leitura é um desses fenômenos, porque, ao longo da história, sua importância, os gestos e os modos de ler foram sendo construídos/desconstruídos, demonstrando que ela é, de fato, uma prática cultural (BOURDIEU; CHARTIER, 1996; CAVALLO; CHARTIER, 1998; CHARTIER, 1991, 2001; MOLLIER, 2009). 
A leitura, quando percebida como ação, é um comportamento que implica uma interação específica e situada, na qual os modos de relação do sujeito com o objeto foram definidos e socializados por práticas culturais formais e informais. Essas práticas são responsáveis pelos diversos modos e modalidades de apreensão do mundo (MADEIRA, 1991, 2003), por determinarem as relações possíveis/possibilitadas a cada indivíduo com os produtos e bens culturais de seu tempo/espaço.

Hébrard (1990), ao descrever a escolarização dos saberes elementares naépoca moderna, assinala o fato de que ainda hoje, no campo das disciplinas universitárias, "não existe um campo de estudos cujo objeto específico seja a leitura" (HÉBRARD, 1990, p. 65), apesar do acesso a qualquer conteúdo de saber pressupor a aprendizagem da leitura. Ferreira (2004), quando caracterizou as tendências teóricas e paradigmáticas da produção acadêmica sobre leitura (realizada sob as modalidades de tese e dissertação em programas de pós-graduação de Letras/ Linguística, Psicologia, Educação, Biblioteconomia, História, Artes, Comunicações), destaca que foi a partir dos anos 90 que passam a ganhar força no interior da academia os temas relacionados aos "leitores com suas representações, preferências, hábitos, histórias; o professor-bibliotecário-leitor [...] o da memória da leitura, do livro e do leitor" (FERREIRA, 2004, p. 20). Tais resultados nos permitem concluir que dessa década em diante as produções legitimadas pela academia começam a focalizar a leitura como uma prática social.

Ainda é a escola do Ensino Fundamental a principal agência social responsável pela aprendizagem inicial da leitura de textos escritos, pelo menos para a maioria da população brasileira que frequenta escolas públicas. É por isso que consideramos importante conhecer o que a leitura é, o que ela representa para os professores, especialmente para os que trabalham em escolas públicas.

Sá (1998), além de circunscrever o que move alguém a realizar um estudo em RS, discorre sobre a necessidade de o pesquisador estar ciente de que "a passagem da apreensão intuitiva da existência do fenômeno para a prática da sua investigação envolve uma transformação." Segundo o autor, há que ocorrer a "construção do objeto de pesquisa. Fenômeno e objeto de pesquisa não são, pois, termos equivalentes" (SÁ, 1998, p. 21, destaques do autor).

Sendo assim, buscaremos apresentar outras razões que nos moveram a propor este trabalho no campo das RS. Iniciaremos com as decorrentes da relevância do fenômeno selecionado, isto é, da leitura, a fim de propormos formalmente o objeto de pesquisa, cientes de que essa construção é apenas uma das aproximações às realidades em que esse fenômeno se faz presente.
Assumimos a posição de Moscovici quando, em sua conversa com Ivana Marková, propôs como estratégia de explicação a "hipótese da polifasia cognitiva" para auxiliar a compreensão de como "as pessoas são capazes, de fato, de usar diferentes modos de pensamento e diferentes representações, de acordo com o grupo específico ao qual pertencem, ao contexto em que estão no momento, etc." (MOSCOVICl, 2010, p. 328). Em vista da coexistência de várias formas de pensamento - quer em uma mesma cultura, quer no mesmo indivíduo -, entendemos que, para compreender as RS de leitura compartilhadas por professores de uma rede de ensino municipal, precisaremos não só de identificar algumas de suas características socioculturais, mas também de descrever cuidadosamente as condições para a coleta e análise dos dados.

Se, por um lado, há que se levar simultaneamente em conta o sujeito e o objeto de representação para a construção de um objeto de pesquisa no campo das representações sociais (SÁ, 1998), por outro, requer-se que sejam anunciados a abordagem, o método e as técnicas de pesquisa utilizadas para a coleta e análise das informações. Como anunciado, a nossa escolha recaiu na proposição teórico-metodológica de Jean-Claude Abric, isto é, na Teoria do Núcleo Central, a qual enfatiza a dimensão estruturante e estruturadora das representações sociais (ABRIC, 1993, 1996, 2000, 2001b).

Quanto ao objeto e sua relevância, é inquestionável a importância da leitura para o exercício e a participação digna e ativa dos indivíduos nas sociedades modernas. Gimeno Sacristán (2008), ao caracterizar o modelo cultural e educativo prevalecente nas sociedades ocidentais, hoje orientado para a busca da formação humana, pondera: "[...] ler e escrever, o que está armazenado na escrita, o capacitar-se para lhe aceder e fazê-lo são aspectos culturais positivamente valorizados." (GIMENO SACRISTÁN, 2008, p. 88). Isso porque esse modelo "concede importância à ação e à atitude de se informar, à leitura como meio de se inserir no mundo enquanto seres reflexivos, continuando a aprender de forma autodidacta a partir do texto escrito [...]" (GIMENO SACRISTÁN, 2008, p. 89).

Concordamos com o autor, quando ele afirma que essa relevância se deveao "valor instrumental que a leitura tem na vida das pessoas para participarem na sociedade do conhecimento", o que converte essa prática cultural "numa condição da cidadania e da inclusão social" (GIMENO SACRISTÁN, 2008, p. 89). Estamos de acordo também com Tedesco (2011, p. 31) quanto à sua recente ponderação acerca dos dois pilares em se deve assentar a educação escolar básica para responder aos desafios do século XXI - "aprender a aprender e aprender a viver juntos" -, caso a escola e os que nela trabalham objetivem 
a construção de uma sociedade mais justa. Não só esses desafios são distintos daqueles do passado, mas o são também as mudanças do papel e do lugar da educação nos dias de hoje, pelo fato de a "globalização crescente em todas as dimensões da sociedade" (TEDESCO, 2011, p. 35) ter gerado como efeito principal o aumento significativo da desigualdade social. Conforme Abreu (1999), a impossibilidade de frequentar uma escola gera repercussões pessoais e sociais (in)contáveis.

Essas ponderações permitem ressaltar a importância da leitura e indicar as condições para sua realização como um dos principais objetos de interesse social e acadêmico. Apesar de sabermos das dificuldades dos resultados da pesquisa acadêmica adentrarem na sala de aula, e cientes de que os principais processos formadores são aqueles que circulam entre os próprios professores dentro das escolas (CHARLOT, 2005), acreditamos que investigações com metas, como as propostas por este trabalho, possam, por seus resultados, subsidiar ações concretas e eficientes para que essas práticas levem professores a acolher, de fato, as novas gerações. Isso porque consideramos a escola como um dos espaços socioculturais fundamentais para a humanização das gerações mais jovens. Assim a percebemos porque, para acolher as gerações mais jovens, essa instituição social deve não só introduzi-las na herança dos saberes simbólicos e discursivos, legitimados socialmente, quanto instrumentalizá-las para que reproduzam e transformem essa herança, sempre que necessário (CARVALHO, 2006). Essa foi uma das razões para a seleção das epígrafes e destaques da entrevista de António Nóvoa (2010), anteriormente citadas.

Assumimos, no campo das RS, as considerações de Guareschi (2008, p. 20), quando, para salientar a importância dos distintos lugares sociais para a constituição das RS, ele afirma: "Tanto a cognição como os afetos que estão presentes nas representações sociais encontram sua base na realidade social. O modo mesmo da sua produção se encontra nas instituições, nas ruas [...] em uma série infindável de lugares sociais".

No Brasil, apesar do aumento significativo das oportunidades educacionais, a população, de modo geral, está longe de atender às demandas socioeconômicas e às demais demandas necessárias para o exercício digno e pleno da cidadania. Isso porque os níveis de escolaridade e de leitura de que essa população dispõe (vide, por exemplo, os resultados do INAF - Indicador de Alfabetismo Funcional, analisados pelo Instituto Paulo Montenegro em 2009) não lhe facultam a condição de uma participação mais ativa e consciente (GOMES; BORUCHOVITCH, 2009).
Por razões sócio-históricas e culturais é a escola que deve ensinar o aluno a ler os diferentes artefatos culturais, sejam eles produzidos com o uso da escrita ou com o auxílio de outras tecnologias e suportes. Assim sendo, não é de estranhar que desde cedo a leitura seja relacionada à escola e ao que nela se realiza e viabiliza com os saberes legitimados para serem aprendidos, como demonstram as falas de crianças matriculadas nos $1^{\circ}$ e $2^{\circ}$ anos do Ensino Fundamental, do estudo conduzido por Gadelha e Carvalho (2007), ao assinalarem que ler serve para estudar, para fazer o dever direito. Algumas delas, para evidenciar a importância da leitura, entendemna como uma forma de fazer o indivíduo ser alguém na vida. $\mathrm{Na}$ população brasileira, a ligação da leitura com a escola é demonstrada em dados de pesquisas nacionais, como os relatados nas edições do relatório Retratos da Leitura no Brasil (AMORIM, 2008). Entre os dados que compunham a amostra representativa da população brasileira em 2007, o não estar estudando foi uma das razões enunciadas para não ler ou frequentar bibliotecas (CUNHA, 2008).

A produção desses sentidos para a leitura pode, ainda, ser considerada como um indício que auxilia a justificar por que 26\% (45,2 milhões de brasileiros de uma amostra que representava $93,2 \%$ da população brasileira com 5 anos de idade ou mais) relacionaram a leitura a conhecimento, conforme dados da pesquisa realizada por Gadelha e Carvalho em 2007. A par disso, cabe ressaltar que um entre cada grupo de quatro participantes dessa pesquisa não faz a menor ideia sobre o papel da leitura (CUNHA, 2008).

Mesmo quando se admite que a inserção dos indivíduos no mundo da escrita faz parte do processo geral da constituição da linguagem, no qual a significação que a escrita tem em uma dada comunidade se expressa, muitas vezes, apenas por interações sociais orais, o fato é que, para a maioria da população, a escola é a instituição formal responsável pela introdução dos indivíduos nas práticas de escrita e leitura legitimadas socialmente.

Havendo demonstrado a importância da leitura e da escola para a inserção do indivíduo na sociedade atual, reiteramos, com outros argumentos, algumas outras razões que nos levaram à escolha da TRS para estudar o objeto de pesquisa.

Entre as implicações mais gerais da TRS, Moscovici destaca aquela que faz essa teoria permitir "que examinemos o aspecto simbólico dos nossos relacionamentos e dos universos consensuais em que nós habitamos" (MOSCOVICl, 2010, p. 105). Para esse autor, cognições, motivações e comportamentos "somente existem e têm repercussões uma vez que eles signifiquem algo e significar implica, por definição, que pelo menos 
duas pessoas compartilhem uma linguagem comum, valores comuns e memórias comuns" (MOSCOVICI, 2010, p. 105).

Ao explicar ancoragem e objetivação como os processos que geram RS, Moscovici (2010, p. 60-78) chama a atenção para as decorrências de classificar e dar nome a alguma coisa, bem como define representação como sendo "fundamentalmente, um sistema de classificação e de denotação de alocação de categorias e nomes." (MOSCOVICI, 2010, p. 62). Acentua ele, ainda: "Quando classificamos [...] nós o confinamos a um conjunto de limites linguísticos, espaciais e comportamentos e certos hábitos." (MOSCOVICl, 2010, p. 63), e conclui: "De fato, a tendência para classificar, seja pela generalização, ou pela particularização, não é, de nenhum modo, uma escolha puramente intelectual, mas reflete uma atitude específica com o objeto." (MOSCOVICI, 2010 , p. 65). Sendo assim, as palavras evocadas por uma frase, como "Leitura é...", podem nos trazer informações, pelo menos em parte, acerca do pertencimento e relações sociais, das práticas e atitudes de quem se proponha a completar essa proposição. Mas, qual a posição que assumimos, como pesquisadoras, acerca de leitura? É o que apresentaremos a seguir.

Tendo por base os distintos e, muitas vezes, concorrentes efeitos da ação social sobre a vida cotidiana, algumas propostas teóricas da Sociologia (ARENDT, 2008; CAVALLO; CHARTIER, 1998; CHARTIER, 1991, 1998, 2001), da Antropologia (ROCKWELL, 2006; GEERTZ, 2007) e da Psicologia Social (MOSCOVICI, 1978, 1993, 2001, 2010, e seus seguidores), sobre a natureza cultural das significações, fundamentam o modo pelo qual passamos a analisar o fenômeno da leitura.

Pensar a realização da leitura como uma produção que acontece em razão dos entendimentos comuns que algum grupo ou instituição constrói pelas ações comunicativas que neles ocorrem em dado período histórico (por exemplo, nos dias de hoje, entre professores de escolas públicas brasileiras), não só é possível como necessário ${ }^{1}{ }^{2}$. Isso porque cada indivíduo, seja ele o que ensina ou o que aprende, compartilha com os demais um dado espaço de cultura e de sentidos que lhe permite se perceber, sentir e avaliar quanto está ou não integrado (NÓVOA, 2010).

\footnotetext{
${ }^{1} \mathrm{~A}$ análise histórica e crítica das ações políticas, especialmente a dos homens letrados sobre os não letrados desde a invenção e uso da escrita, realizada por Ricardo Paseyro, em 1990, é um exemplo de como a linguagem, e especificamente a língua, estão a serviço de algum poder.

${ }^{2}$ Para uma análise histórica da escrita em escolas e das representações sociais mais importantes com repercussão nos sistemas escolares e na sua regulamentação no Brasil, a leitura do texto "Ensino da escrita e escolarização dos corpos: uma perspectiva histórica", de Faria Filho (2001), é interessante e inspiradora.
}

Sendo a escola uma das instituições que, por seus fazeres, propicia aos alunos sentirem-se ou não incluídos (MUSIS; CARVALHO, 2010), e visto ser a leitura socialmente valorizada e sentida pelo indivíduo desde a sua infância como imprescindível para o atendimento das necessidades básicas de sobrevivência (GADELHA; CARVALHO, 2007), o que essa instituição, pelas práticas educativas de seus professores, pode e deve fazer para que os alunos se sintam incluídos como cidadãos leitores?

Educadores, como António Nóvoa, defendem a priorização do conhecimento e da cultura no currículo escolar, em relação a quaisquer outras ações. Interessa aqui, entretanto, a posição de Nóvoa (2010), quando retoma Olivier Reboul para enfatizar que a escola deve ensinar tudo o que une e tudo o que liberta. Na opinião desse educador e sociólogo, compete à escola ensinar as ferramentas básicas do conhecimento e da cultura, pois só assim as desigualdades sociais e de oportunidades podem ser menos agudas. De acordo com ele,

[...] em vários países, embora a política educacional seja única, verifica-se um dualismo cada vez mais acentuado: as elites investem na Educação privada, cuja base estrutural é a aprendizagem, enquanto as escolas públicas estão cada vez mais centradas em dimensões sociais e assistenciais.

Essa Educação feita em duas velocidades é o pior dos cenários para o nosso futuro, pois só aumenta a desigualdade de oportunidades. (NÓVOA, 2010, s. p., grifos nossos.)

No Brasil não é diferente. Os diversos relatórios disponibilizados pelo INEP (Instituto Nacional de Estudos e Pesquisas Educacionais Anísio Teixeira) acerca do desempenho de alunos da Educação Básica em avaliações de âmbito nacional, como os realizados pelo Sistema Nacional de Avaliação da Educação Básica (Saeb) e pelo Censo Escolar, demonstram diferenças que favorecem os alunos matriculados em escolas privadas quando comparados aos matriculados nas redes públicas (municipal, estadual e federal).

Em parte, as oportunidades de acesso à leitura e sua realização na escola tanto decorrem dos efeitos da hegemonia que assumem determinados discursos - como os discursos oficiais ${ }^{3}$ formulados pelo governo federal e pelos governos dos estados e municípios, ao buscarem regular seu ensino (PCNs e Diretrizes Curriculares, por exemplo), conforme analisaram Marinho (2003; 2006; 2007) e Pullin (2010) - quanto dependem especialmente dos significados que instituem as concepções e crenças dos professores acerca de leitura (SILVA, 1999a).

Tendo em vista que compartilhamos as principais preocupações demonstradas pelas

\footnotetext{
${ }^{3}$ O texto de Traversini e Buaes (2009) sinaliza alguns efeitos dos discursos predominantes nas práticas docentes.
} 
investigações derivadas da proposição inicial de Serge Moscovici e do pressuposto de que as tentativas de explicação do mundo e dos objetos sociais constituem-se em RS que se revelam nas falas e ações dos indivíduos, como nos reitera Abric (1994), resta-nos apresentar a parte empírica da investigação que realizamos.

\section{Método}

A natureza do objeto deste trabalho e o conjunto de inquietações que o atravessaram e o limitam, isto é, as relacionadas à identificação e análise das RS de leitura de professores de Ensino Fundamental para que futuramente pudéssemos propor alguma ação de formação junto a eles, encaminharam-nos para a realização de uma pesquisa exploratória de natureza qualiquantitativa.

A parte empírica do trabalho foi realizada junto a professores que trabalhavam na rede municipal de ensino de uma cidade de porte médio do interior do estado do Paraná. Esse município diferencia-se da maioria dos municípios por ofertar, há mais de dez anos, o ensino em tempo integral para alunos do Ensino Fundamental. Contava, na época, com uma rede de 37 escolas que acolhia 8.868 alunos matriculados, desde o Pré ${ }^{4}$ até a $8^{a}$ série. Um total de 627 professores, contratados por concurso público, atendia esses alunos.

A pesquisa foi aprovada pelo Comitê de Ética em Pesquisa da Universidade Estadual de Londrina (CEP/UEL 231/2010), e executada após a assinatura dos Termos de Consentimento pelos responsáveis das escolas e pelos professores que assim confirmaram sua adesão livre e voluntária.

A amostra do presente trabalho contou com a participação de 445 docentes, isto é, com aproximadamente $71 \%$ dos professores que atuavam nas escolas desse município.

Dois instrumentos foram utilizados para a coleta de dados propriamente dita: um questionário para a identificação dos participantes, construído para a obtenção de três conjuntos de informação: dados pessoais, formação profissional e experiência profissional; e um Teste de Associação Livre de Palavras, formulado conforme recomendações de Abric (1993, 2000, 2003).

Esse teste viabiliza a obtenção de informações que configuram o Núcleo Central e o Núcleo Periférico das RS. Como tal, é uma ferramenta que permite ao pesquisador estruturar as respostas apresentadas a um estímulo verbal indutor, em situações de evocação espontânea e imediata, bem como identificar os universos semânticos relacionados a esse indutor. No Brasil, esse teste tem sido utilizado em pesquisas, por exemplo, por Pereira (1997); Schulze (1995); Almeida e Costa (1999), Alves-Mazzotti (2007, 2011); Gomes, (2009); Menandro e Souza (2010); Machado e Aniceto (2010). No caso da presente pesquisa, foi utilizada como indutora a frase "Leitura é...".

Nos protocolos desse teste, nas linhas iniciais era solicitado ao participante que informasse seu nome, a data de aplicação e a escola. Logo após, a seguinte instrução foi colocada: "Você deverá completar a frase 'Leitura é...' com os primeiros cinco termos que vierem à sua mente. Após a escrita dessas palavras, você deverá elencar a importância delas no parêntese que antecede a linha de cada palavra que escreveu. Coloque o número 1 para a que considera a mais importante. Numere as demais, também, por ordem de importância."

Duas etapas gerais estruturaram o caminho percorrido para a coleta de dados: a primeira teve o intuito de obter autorização para a execução da parte empírica, e a segunda para a coleta propriamente dita dos dados. Para a execução da primeira etapa, inicialmente foi exposto o projeto de pesquisa ao responsável pela secretaria que gerencia as ações municipais no campo da educação. Depois de obtida sua aprovação, uma das pesquisadoras que trabaIhava como assessora pedagógica nessa secretaria aproveitou a realização de uma reunião com todas as diretoras e coordenadoras das escolas da rede para apresentar o projeto de pesquisa e obter o consentimento delas para a execução desse projeto em suas escolas. Depois de obtido esse consentimento, foi realizada uma visita a cada unidade e agendado o encontro com os professores no horário em que os alunos se encontrassem envolvidos em outras atividades e não dependessem da presença desses professores.

O procedimento da coleta dos dados foi coletivo por escola e conduzido pela mencionada pesquisadora em uma das salas de aula. Após uma apresentação oral sobre o intuito da investigação, a pesquisadora entregou a cada um dos presentes uma folha impressa com o Termo de Consentimento Esclarecido. Logo que devolveram à pesquisadora o termo assinado, ela entregou individualmente o protocolo de cada instrumento selecionado para a coleta, na ordem em que foram anteriormente descritos. Os que não concordaram em assinar esse termo foram convidados a se retirar da sala.

\footnotetext{
${ }^{4} \mathrm{~A}$ nomenclatura encontrava-se em processo de transição, visto que o município estava se adequando à oferta desse ensino em nove anos.
}

Práxis Educativa, Ponta Grossa, v.6, n.2, p. 207-222, jul.-dez. 2011. Disponível em <http://www.periodicos.uepg.br> 


\section{Resultados e Discussão}

De modo geral, poucas foram as dúvidas que tiveram de ser esclarecidas nas duas etapas do procedimento. Na etapa da aplicação dos instrumentos os esclarecimentos necessários foram raros e prestados individualmente.

Esta seção apresenta, inicialmente, a caracterização dos participantes, porque, como ensinou Moscovici (2010, p. 334), "Somente dentro da realidade histórica e cultural as relações de razão e na razão podem ser plenamente avaliadas e compreendidas."

Com exceção de um, cuja idade era 54 anos, os demais participantes são do sexo feminino, com idade entre 20 a 79 anos: a idade da maioria $(80,2 \%)$ variava entre 30 e 39 anos; a de 13,9\%, entre 50 e 69 anos; a de $11,9 \%$ estava entre 20 a 29 anos, e a de uma das participantes era de 79 anos.

Quanto ao início da experiência profissional deles, como professores, constatamos que a mais idosa iniciou em 1961; $63 \%$ começaram a trabalhar entre 1991 e 2010; e, destes, 70,4\% iniciaram o trabalho entre 1991 e 2000. Quanto à formação acadêmica profissional, verificamos que 28 contavam apenas com formação no Ensino Médio em Magistério. Os demais professores $(93,7 \%)$ dispunham de formação no Ensino Superior, sendo que a maioria deles $(87,4 \%)$ havia optado por licenciatura em Pedagogia $(35,7 \%)$, licenciatura obtida em cursos do Normal Superior $(10,8 \%)$; e outras licenciaturas $(40,9 \%)$. Em outras palavras, 389 participantes dispunham da formação inicial específica exigida para o exercício das funções que cumpriam profissionalmente. Mais da metade dos participantes $(66,7 \%)$ concluiu algum curso de especialização: $63 \%$ na área de Educação e os demais em outras áreas.

A maioria dos participantes $(82,7 \%)$ iniciou sua profissão em escolas da rede pública. Apenas seis começaram a trabalhar na rede pública e particular simultaneamente. A experiência dos participantes, como professores da rede municipal, variava de um a 45 anos: $62,2 \%$ contavam com mais de 12 anos de experiência, e $9 \%$ com, no máximo, um ano de experiência.

Como pudemos constatar, os professores participantes apresentam algumas características comuns, como as relacionadas ao gênero e faixa etária, predominantes entre os profissionais que atuam no Brasil, especialmente na Educação Básica. Conforme dados fornecidos pelo INEP (BRASIL, 2011), em 2009, dos 1.997 .978 professores que atuavam na Educação Básica, mais de $81 \%$ eram do sexo feminino, com faixa etária similar à dos participantes. Desse total, 5,9\% tinham idade inferior a 25 anos e $12,7 \%$ estavam com mais de 50 anos. Os dados dos participantes demonstram essa tendência, no item idade: apenas $1,9 \%$ deles tinham idade inferior a 25 anos, e 13,7\% mais de 50 anos.

Em relação à formação acadêmica, 94\% dos professores que atuavam na Educação Básica no Brasil, segundo o citado relatório, possuíam alguma licenciatura. Como descrito, esse índice entre os participantes deste estudo foi de $87,4 \%$.

Como se pode verificar, o perfil dos participantes é similar ao da maioria dos professores que atuam nas escolas públicas e particulares do Brasil. São, ainda, as mulheres que predominam no exercício desse ofício.

Produções como as de Manguel (1997) e Chartier (2001), entre outras, são exemplos que documentam que o ingresso das mulheres, como leitoras e produtoras de textos, é historicamente posterior ao dos homens. Entretanto, hoje são elas que, na maioria das escolas, ensinam a ler, como demonstram os dados de âmbito nacional, coletados pelo INEP, e os dados dos participantes deste estudo.

Sendo assim, o que as professoras pensam, associam e valorizam a respeito da leitura é sumamente importante e de relevância social, em vista dos efeitos das suas ações educativas em sala de aula. Pullin e Moreira (2008), apesar de terem investigado as práticas de prescrição e de leitura junto a alunos e professores do magistério, concluem, pelos dados que levantaram, que os modos como os professores prescrevem os textos de leitura para seus alunos afetam as condições para que cada um deles (re)escreva os entendimentos sobre si e o mundo.

Em face do aporte teórico adotado passaremos, então, para a apresentação da análise dos aspectos estruturais das representações sociais acerca da leitura construídas pelos participantes, isto é, pelos 445 professores que na época da pesquisa atuavam na rede municipal de ensino, foco deste estudo. Para obter e analisar essas informações foi adotado o método das evocações livres, conforme proposto desde 1994 por Abric.

A variedade de palavras associadas ao termo indutor "Leitura é..." foi muito grande. Todos os participantes escreveram as cinco palavras solicitadas para o indutor e as classificaram; portanto o corpus inicial de que dispúnhamos totalizou 2.225 palavras.

Para analisar essas palavras foi usado o software Ensemble de programmes permettant l'analyse des evocations (EVOC), versão 3 de 2000, desenvolvido por Pierre Vergès. Esse software possibilita identificar a organização das palavras em função da hierarquia implícita dada pela combinação da frequência $(F)$ com a ordem natural de evocação (OME). A técnica de análise permite identificar um 
quadro de quatro casas, no qual são distribuídas as palavras evocadas, que discriminam os elementos do sistema central e periférico da representação. segunda periferia da representação social de leitura, objeto deste trabalho.
Neste estudo adotamos o procedimento utilizado por Lima (2009), isto é, ao invés de considerarmos a ordem natural das evocações (OME), consideramos a hierarquização efetuada pelos participantes no momento da coleta dos dados e, portanto, a ordem média de importância (OMI) de cada palavra associada ao indutor verbal. Do mesmo modo, utilizamos a média das ordens médias dos elementos mais frequentes hierarquizados como mais importantes (MOMI).

Conforme disposto no Manual desse Programa (VERGĖS, 1999), quando se verifica uma grande variação lexical nos dados colhidos, inicialmente, deve-se proceder a algumas transformações. Feitas as transformações recomendadas, das 2.241 palavras recolhidas restaram 269 (12\%) diferentes. Observamos que a palavra "conhecer" apareceu com o maior número de evocações (268), enquanto 498 palavras foram evocadas apenas uma vez.

Apresentamos o Quadro 1, que foi

Quadro 1 - Possível composição do Núcleo Central e do Sistema Periférico da representação social de leitura

\begin{tabular}{|c|c|c|c|c|c|}
\hline \multicolumn{3}{|c|}{ Frequência $\geq 54$ com média $<3,0$} & \multicolumn{3}{|c|}{ Frequência $\geq 54$ com média $\geq 3,0$} \\
\hline Evocação & $\mathbf{F}$ & OMI & Evocação & $\mathbf{F}$ & OMI \\
\hline conhecer & 268 & 1,847 & prazer & 241 & 3,237 \\
\hline informar & 146 & 2,452 & viagem & 64 & 3,734 \\
\hline aprender & 136 & 2,529 & lazer & 65 & 3,954 \\
\hline cultura & 139 & 2,554 & diversão & 67 & 4,045 \\
\hline interpretar & 60 & 2,950 & & & \\
\hline \multicolumn{3}{|c|}{ Frequência $<54$ com média $<3,0$} & \multicolumn{3}{|c|}{ Frequência $<54$ com média $\geq 3,0$} \\
\hline Evocação & $\mathbf{F}$ & OMI & Evocação & $\mathbf{F}$ & OMI \\
\hline essencial & 48 & 2,021 & imaginar & 49 & 3,327 \\
\hline atualização & 12 & 2,333 & relaxamento & 18 & 3,722 \\
\hline compreender & 48 & 2,750 & desenvolver & 19 & 3,737 \\
\hline decodificar & 26 & 2,769 & sonhar & 18 & 3,944 \\
\hline necessidade & 21 & 2,810 & entretenimento & 23 & 3,957 \\
\hline descobrir & 43 & 2,884 & emocionar & 25 & 4,040 \\
\hline sabedoria & 53 & 2,868 & aventura & 13 & 3,231 \\
\hline importante & 18 & 2,889 & distração & 12 & 4,500 \\
\hline comunicação & 21 & 2,952 & enriquecimento & 17 & 3,000 \\
\hline \multirow[t]{4}{*}{ crescimento } & 16 & 2,750 & experiência & 12 & 3,750 \\
\hline & & & hábito & 16 & 3,813 \\
\hline & & & necessária & 14 & 3,214 \\
\hline & & & útil & 15 & 3,400 \\
\hline
\end{tabular}

Fonte: Organizado pelos autores.

Como pode ser verificado, no primeiro quaconstruído com o auxílio do software EVOC. Um dos seus programas, o Rangfrq (também chamado de Tabrgfrq), organiza, em um quadro de quatro casas, os elementos que compõem o provável núcleo central e a periferia de uma representação.

Esse quadro registra os resultados da consideração simultânea da frequência $(F)$, com a ordem média da importância (OMI) atribuída pelo participante a cada uma das palavras que evocou. A frequência estipulada para a distribuição das palavras nos quadrantes teve por referência o valor 54 e um mínimo de 12. Um total de 24 palavras atendeu a esse critério. Em cada quadrante foram, ainda, hierarquizadas em ordem decrescente de frequência as palavras com suas respectivas OMls. Para interpretar o quadro, seguimos as recomendações de Oliveira et al. (2005) usadas recentemente por Machado e Aniceto (2010). Por conseguinte, tomamos as cinco palavras do quadrante superior esquerdo como constituintes, muito provavelmente ${ }^{5}$, do núcleo central da representação; as quatro do quadrante superior direito como indicativas da primeira periferia; as 10 do quadrante inferior esquerdo como as de contraste; e, por fim, as 13 do quadrante inferior direito como elementos da

\footnotetext{
${ }^{5}$ A razão de usarmos o qualificativo 'provável/provalvelmente' para considerar o núcleo central da representação deve-se ao fato de que seus elementos constituintes não foram, posteriormente, testados para verificação da sua centralidade. Como ensina Abric (2003, p. 64), "nem tudo o que se encontra nessa casa é central, mas o núcleo está nessa casa”.
}

drante estão situadas, como prováveis elementos do núcleo central da representação social de leitura, as palavras: "conhecer; informar; aprender, cultura, interpretar". Como principais elementos periféricos dessa representação, distribuídos nos três demais quadrantes, as palavras "prazer" e "viagem", as de menor OMI, entre as demais, isto é, entre as que apresentaram uma $\mathrm{F} \geq 54$ e uma $\mathrm{OMI} \geq 3,0$. Apesar da palavra "prazer" ter sido a segunda mais evocada $(F=241)$, sua $\mathrm{OMI}(3,237)$ foi superior às obtidas pelas palavras que constituem o provável NC da RS em estudo. No quadrante inferior esquerdo $(\mathrm{F}<54$; OMl $<3,0)$ registramos a presença de 10 palavras, que constituiem a zona de contraste, e no quadrante inferior direito, segunda periferia, as 13 palavras que apresentaram $F<54$ e OMI $\geq 3,0$. Desse último quadrante destacamos as palavras: "imaginar" $(\mathrm{OMI}=3,327)$ e "relaxante" $(\mathrm{OMI}=3,722)$, por apresentarem as menores OMls nesse quadrante. Podemos dizer que esse conjunto de elementos distribuídos nos quadrantes indica o universo simbólico que abriga a gama de sentidos atribuídos pelos professores participantes à leitura.

O fato de as palavras "conhecer", "informar", "aprender", "cultura" e "interpretar" se localizarem no quadrante do possível NC da representação e das três primeiras terem sido evocadas por mais de $30 \%$ dos participantes certamente se deve aos 
efeitos das práticas culturais, sociais e escolares experienciadas por esses professores. Seja em propagandas comerciais, de proposição de políticas públicas de incentivo à leitura seja nas relativas à proposição de práticas educativas escolares, frequentemente são ressaltadas essas funções da leitura (GIMENO SACRISTAN, 2008; TEDESCO, 2011; BRASIL, 2009, 2010). Como salientam, ainda, Bourdieu e Chartier (1996), atualmente, em sociedades letradas, a leitura é, sem dúvida, uma atividade importante para que o indivíduo possa ficar informado e ter acesso a outros saberes, além de poder se conhecer e agir (FREIRE, 1982; 2001).

Como o sistema periférico é um complemento indispensável do sistema central (ABRIC, 1993, $1994,2000,2001$ ), porque protege, atualiza e contextualiza constantemente suas determinações normativas, permitindo aos sujeitos uma flexibilidade e adequação em função de suas experiências cotidianas, bem como entendendo que as RS são constituídas por uma estrutura particular, composta de crenças-nucleares que permitem aos indivíduos armazenar e partilhar crenças básicas, que estruturam e, ao mesmo tempo, integram os efeitos das distintas experiências individuais (MOSCOVICl, 2002), além dos elementos que compõem o provável NC das RS de leitura dos participantes deste estudo, é necessário que seja apresentada a interpretação que a leitura dos demais quadrantes do Quadro 1 nos permitiu. Esses elementos constituem, como diz Alves-Mazzotti (2002, p. 22), "a parte operatória da representação, desempenhando um papel essencial no funcionamento e na dinâmica das representações."

Como se pode ler nesse quadro, das 17 palavras que constituem o quadrante superior e inferior à direita, indicativas respectivamente da primeira e quarta periferia dessa representação, as seguintes palavras obtiveram menor média (OMI) por quadrante: no quadrante direito superior, "prazer" ( $F=241, \mathrm{OMl}=3,237)$, "viagem" $(F=64, \mathrm{OMI}=3,734)$; e no quadrante inferior direito, "imaginar" ( $F=49, \mathrm{OMI}=3,327)$, "relaxamento" $(F=18$, $\mathrm{OMI}=3,722$ ).

A realização de leitura como recurso importante para o indivíduo conhecer, obter informação e aprender parece ser o universo simbólico principal no qual habitam os sentidos de leitura para esses participantes. Um universo no qual a função instrumental da leitura supera a da vivência ao ler. Cabe destacar que o fato de defendermos a leitura como experiência não implica dizermos que todas as leituras devam despertar, por exemplo, prazer, mas que os leitores devem se relacionar com elas em função do que cada uma, em suas múltiplas especificidades, tem a oferecer (KRAMER; OSWALD, 2002).

De modo geral, os termos constituintes do primeiro quadrante do sistema periférico (prazer; viagem; lazer; diversão), de formação mais recente, parecem refletir os efeitos das campanhas educativas e publicitárias sobre leitura, porém com força não suficiente para alterar o universo simbólico principal evidenciado no Quadro 1. Apesar de o termo "prazer" ter sido evocado com uma frequência alta $(F=241$, isto é, evocado por mais de $50 \%$ dos participantes), o efeito do trabalho cognitivo na hierarquização das palavras que os professores escreveram resultou em uma $\mathrm{OMI}=3,237$, a qual, no que concerne à importância atribuída pelos participantes, nos informa que prazer situa-se abaixo de $50 \%$ das opções possibilitadas pelo instrumento.

Entretanto, como propõe Flament (1994, p, 86), "o núcleo pode delegar a gestão de uma parte da periferia a uma subestrutura periférica, por razões de economia", uma vez que "um elemento periférico saliente tira sua saliência de uma relação com o núcleo central, e sua característica periférica, de sua realização condicional." (FLAMENT, 1994, p. 88). Verificados os índices de relação entre os termos do segundo quadrante com os do primeiro, isto é, dos que compõem o possível NC, a associação mais forte $(0,38)$ foi constatada entre prazer e conhecer, o que indica que para os participantes deste estudo o prazer em ler textos que permitam conhecimento se constitui em uma possibilidade.

Resultados similares foram constatados por Gomes (2009) junto a professores do Ensino Médio da cidade mais próxima e importante do município onde esta pesquisa foi realizada. Essa autora registrou que as palavras evocadas com maior frequência ao mesmo instigador verbal usado nesta pesquisa foram: prazer e conhecimento, que obtiveram a mesma frequência; lazer e informar, seguidas das palavras cultura, aprendizado e importante.

\section{Considerações Finais}

Entendendo que a história de vida e de trabaIho dos professores vai sendo consolidada paulatinamente por sua prática pedagógica (NÓVOA, 1992; SILVA, 1999a) e pela síntese dialética que gera as representações construídas acerca do mundo, dos saberes, dos valores, das atitudes e das práticas que devem ensinar, e levando em conta que esse profissional, no exercício de suas funções, "não só informa, mas também forma aqueles com quem convive" (SILVA, 1999b, p. 22), consideramos que pesquisas que têm por referencial a TRS são necessárias e importantes no campo da Educação, como já foi assinalado por Alves-Mazzoti (1994), Madeira (2003) e Souza (2000; 2002), por exemplo. 
Os resultados deste estudo vêm ao encontro de outros, realizados com professores de outras instituições escolares que também focalizaram as RS de leitura desses professores (BARRETO, 2006; SAVELI, 2001; MAGALHÃES, 2005; GOMES; PULLIN, 2010).

Por admitirmos que as RS "permitem a abordagem do domínio simbólico e a análise da interpretação que os actores dão à sua prática." (VERGĖS, 2005, p. 201), podemos constatar neste estudo que o sentido primeiro de leitura, compartilhado pelos participantes, configura essa ação como parte de um processo instrumental para a obtenção de conhecimento, de informação, de aprendizagem e de cultura, ao interpretarem os textos. Para alguns desses participantes, esse sentido não impede que, ao ler um texto, o façam por diversão, lazer; e especialmente para $54,16 \%$ deles, que realizem essa leitura com prazer. Esse universo simbólico, no qual se inscrevem os termos selecionados e hierarquizados pelos participantes, decorre, a nosso ver, de um contexto que inclui uma série de fatores histórico-culturais que instigam para o entendimento, por exemplo, de que o conhecimento e o saber restringem-se ao que está escrito.

Sendo a escrita um instrumento que, antes de tudo, é um poderoso meio de manipulação da sociedade, e por sabermos que a escola ocupa uma posição privilegiada socialmente para ensinar as novas gerações a ler e a escrever, esse sentido de leitura compartilhado pelos participantes precisa ser objeto de reflexão por parte não só desses professores, mas também daqueles que estão preocupados com a qualidade das práticas educativas que ocorrem no cotidiano das escolas.

Cientes de que as RS podem ser vistas "como um guia para a ação" (ABRIC, 1994, p. 13), e de que nosso estudo apenas situa a organização do provável núcleo central e dos elementos do sistema periférico da representação de leitura em um grupo de professores, não podemos cair na armadilha de propor inferências deterministas tendo por base unicamente o que constatamos. Reiteramos que esses resultados são indícios prováveis das "práticas representadas e não das práticas efetivas" (ALVES-MAZZOTTI, 2002, p. 24) dos participantes. Anunciamos que uma das metas deste trabalho era que seus resultados pudessem subsidiar ações futuras de formação docente continuada. Assim será feito. Porém, em face das diretrizes teóricas que fundamentam este trabalho, isto é, da abordagem estrutural, necessitamos ainda, com o corpo de resultados e da interpretação realizada, ressituar as RS de leitura dos participantes em seu contexto e compreender suas ligações com o conjunto de fatores psicológicos, cognitivos e sociais (ALVES-MAZZOTTI, 2002), porque apenas o primeiro passo nessa direção foi concluído.
Este trabalho foi, por conseguinte, apenas um início para que uma de suas metas possa ser alcançada, visto que nos foi dado a conhecer unicamente o conteúdo dessa representação, sua estrutura interna e seu provável núcleo central. Além de testar a centralidade dos elementos identificados como mais significativos, de ter a segurança de que esses são os sentidos inegociáveis, pois se forem retirados da representação, ela perde seu significado (ALVES-MAZZOTTI, 2002), resta-nos refletir e construir uma interpretação sobre como esses elementos que constituem a representação de leitura "se relacionam ao contexto $e$ às atitudes, aos valores, às referências dos sujeitos" (ALVES-MAZZOTTI, 2002, p. 25).

Para que tenha êxito, a proposição de qualquer programa que vise à formação continuada dos professores participantes deste estudo depende, ainda, de outros resultados a serem obtidos com o uso de outras estratégias metodológicas e técnicas, dentre as quais podemos citar: a observação das práticas cotidianas desses professores em sala de aula, a realização de entrevistas e a utilização de outros recursos de análise, como os que permitem a análise de similitude (VERGĖS, 1999).

Para concluir, indicamos a necessidade da produção de outras investigações, como, por exemplo, das que possibilitem análises que, além de determinarem a especificidade da representação, possam identificar a sua relação com outras representações que the sejam vizinhas e a incluam, como foi sugerido por Abric (2001a). $\mathrm{O}$ uso de instrumentos e técnicas complementares aos utilizados neste estudo, e a tomada de outras direções e aprofundamentos, alguns deles indicados ao longo do texto, poderão desvelar quais sentidos comuns, quais sistemas de significação estão inscritos na linguagem e nas práticas educativas escolares de leitura, possibilitando aos professores uma melhor compreensão das representações sociais e das práticas de leitura.

\section{Referências}

ABREU, M. "Quem não lê e não escreve da vida pouco desfruta, porém...". In: BARZOTTO, V. H. Estado da leitura. Campinas, SP: Mercado de Letras; Associação de Leitura do Brasil, 1999. p. 179-192.

ABRIC, J. C. Central system, peripherical system: their functions and roles in the dynamics of social representations. Papers on Social Representations, v. 2, n. 2, p. 75-78, 1993.

Pratiques sociales et représentations. Paris: Presses Universitaires de France, 1994.

Specific processes of social representations. Papers on Social Representations, v. 5, n. 1, p. 7780, 1996. 
A abordagem estrutural das representações sociais. Tradução de Pedro H. Faria Campos. In: MOREIRA, A. S. P.; OLIVEIRA, D. C. de. Estudos interdisciplinares de representação social. 2. ed. Goiânia: Ab, 2000. p. 27-46.

L'approche structurale des représentations sociales: development récentes. Psychologie \& Société, Aix-en-Provence, v. 4, p. 81-103, 2001a.

O estudo experimental das representações sociais. In: JODELET, D. (Org.). Representações sociais. Rio de Janeiro: EdUERJ, 2001b. p. 155-171.

Méthodes d'études des representations sociales. Saint-Agne: ÉRÈS, 2003.

ALMEIDA, A. M. de O.; COSTA, W. A. da. Teoria das representações sociais: uma abordagem alternativa para se compreender o comportamento cotidiano dos indivíduos e dos grupos sociais. Revista Educação Pública, Cuiabá, v. 8, n. 13, p. 250-280, jan./jun. 1999.

ALVES-MAZZOTTI, A. J. Representações sociais: aspectos teóricos e aplicações à Educação. Em Aberto, Brasília, v. 14, n. 61, p. 60-78, jan./mar. 1994.

. A abordagem estrutural das representações sociais. Psicologia da Educação: Revista de Estudos Pós-Graduados em Psicologia da Educação, São Paulo, v. 14/15, p. 17-37, jan./dez. 2002.

Representações da identidade docente: uma contribuição para a formulação de políticas. Ensaio: avaliação, políticas públicas, educação, Rio de Janeiro, v. 15 , n. 57 , p. 489-594, out./dez. 2007. DOI: 10.1590/ S0104-40362007000400008

Formação para o magistério: o discurso dos formadores. Revista Diálogo Educacional, Curitiba, v. 11, n. 33, p. 287-307, maio/ago. 2011.

AMORIM, G. (Org.). Retratos da leitura no Brasil. São Paulo: Imprensa Oficial; Instituto Pró-Livro, 2008.

ARENDT. A. O cotidiano e a história. 8. ed. São Paulo: Paz e Terra, 2008.

BARRETO, D. A. B. Representação social do professor da educação de jovens e adultos. 2006. 238 f. Tese (Doutorado em Educação) - Faculdade de Educação, Universidade Federal da Bahia, Salvador, 2006.

BOURDIEU, P.; CHARTIER, R. A leitura: uma prática social - debate entre Pierre Bourdieu e Roger Chartier. In: CHARTIER, R. Práticas de leitura. São Paulo: Estação Liberdade, 1996. p. 221-226.

BRASIL. Ministério da Educação. Plano de Desenvolvimento da Educação. 2009. Disponível em: <http://www.oei.es/salactsi/provabrasil_matriz. pdf>. Acesso em: 15 dez. 2010.

. Ministério da Educação e Ministério da Cultura. Caderno do PNLL. Estado e sociedade atuando pelo desenvolvimento da leitura no Brasil. 2010. Disponível em: <www.pnll.gov.br>. Acesso em: 15 mar. 2011.
INEP. Sinopse do Professor Relatório atualizado em 2011. Disponível em: <http://www.inep. gov.br/basica/censo/Escolar/sinopse/sinopse.asp>. Acesso em: 15 mar. 2011.

CARVALHO, J. S. F. de. Acolher no mundo: educação como iniciação nas heranças simbólicas comuns e públicas. In: BARBOSA, R. L. L. (Org.). Formação de educadores: artes e técnicas - ciências e políticas. São Paulo: EDUNESP, 2006. p. 53-60.

CAVALLO, G.; CHARTIER, R. História da leitura no mundo ocidental. São Paulo: Ática, 1998.

CHARLOT, B. Relação com o saber, formação de professores e globalização. Porto Alegre: Artmed, 2005.

CHARTIER, R. O mundo como representação. Estudos Avançados, São Paulo, v. 5, n. 11, p. 173-191, jan./abr. 1991. DOI: 10.1590/S0103-40141991000100010

Práticas de leitura. Tradução de Cristiane Nascimento. São Paulo: Estação da Liberdade, 1998.

Cultura escrita, literatura e história. Porto Alegre: Artmed, 2001.

CUNHA, M. A. A. Acesso à leitura no Brasil. In: AMORIM, G. (Org.). Retratos da leitura no Brasil. São Paulo: Imprensa Oficial: Instituto Pró-Livro, 2008. p. 49-60.

FARIA FILHO, L. M. Ensino da escrita e escolarização dos corpos: uma perspectiva histórica. In:

Modos de ler/formas de escrever: estudos de história da leitura e da escrita no Brasil. 2. ed. Belo Horizonte: Autêntica, 2001. p. 29- 46.

FERREIRA, N. S. de A. Leitura como objeto de investigação. Educação \& Contemporaneidade, Salvador, v. 13, n. 21, p. 13-22, 2004.

FLAMENT, C. Aspectes périphériques des représentations sociales. In : GUIMELLI, C. Textes de base en sciences sociales. Paris: Delachaux et Niestlé, 1994. p. 85-118.

FREIRE, P. Da leitura do mundo à leitura da palavra. (Entrevista concedida a Ezequiel Theodoro da Silva). Leitura: Teoria e Prática, Campinas, v. 1, p. 3-9, nov. 1982.

Ensinar, aprender: leitura do mundo, leitura da palavra. Estudos Avançados, São Paulo, v. 15, n. 42 , p. 259-268, maio/ago. 2001. DOI: 10.1590/S010340142001000200013

GADELHA, M. J. de A; CARVALHO, M. do R. de F. de. Ler serve prá estudar: representações sociais das crianças do ensino fundamental. In: JORNADA INTERNACIONAL, 5.; CONFERÊNCIA BRASILEIRA SOBRE REPRESENTAÇÕES SOCIAIS, 3., Brasília, 2007. Anais ... Brasil: Edunb, 2007. p. 1-12.

GEERTZ, C. O saber local: novos ensaios sobre a antropologia interpretativa. Tradução de Vera Mello Joscelyne. 9. ed. Petrópolis:Vozes, 2007. 
GIMENO SACRISTÁN, J. A educação que ainda é possível. Ensaios sobre a cultura para a educação. Porto: Portoed, 2008. p. 85-109.

GOMES, M.A. M. dos;BORUCHOVITCH, E. Proficiência em leitura: um panorama da situação. In: SANTOS, A. A. A. dos S.; BORUCHOVITCH, E.; OLIVEIRA, K. L. de. Cloze: um instrumento de diagnóstico e intervenção. São Paulo: Casa do Psicólogo, 2009. p. 23-46.

GOMES, M. de C. A leitura nas representações sociais de professores do ensino médio. 2009. 118 f. Dissertação (Mestrado em Educação) - Universidade Estadual de Londrina, Londrina, 2009.

GOMES, M. de C.; PULLIN, E. M. M. P. Valoração da leitura por recém-ingressos em Pedagogia: reflexões para a prática docente. Arquivos Brasileiros de Psicologia, Rio de Janeiro, v. 62, n. 3, p. 80-92, 2010.

GUARESCHI, P. Introdução. In: JOVCHELOVITCH, S. (Orgs.). Textos em representações sociais. 10. ed. Petrópolis, RJ: Vozes, 2008. p. 17-28.

GUARESCHI, P.; JOVCHELOVITCH, S. (Orgs.). Textos em representações sociais. 10. ed. Petrópolis, RJ: Vozes, 2008.

GUILLY, M. As representações sociais no campo da educação. In: JODELET, D. As representações sociais. Tradução de Lilian Ulup. Rio de Janeiro: EdUERJ, 2001. p. 321-341.

HÉBRARD, J. A escolarização dos saberes elementares na época moderna. Revista Teoria e Prática da Educação, Porto Alegre, n. 2, p. 65- 109, 1990.

JODELET, D. Social representations: the beautiful invention. Journal for the Theory of Social Behavior, v. 38, n. 4, p. 411-430, 2008.

KRAMER, S.; OSWALD, M. L. Leitura e escrita de professores em três escolas. In: FREITAS, M. T. A.; COSTA, S. R. (Orgs.). Leitura e escrita na formação de professores. Juiz de Fora, MG: UFIF, 2002. p. 9-28.

LIMA, A. M de. O "bom aluno" nas representações sociais de professoras da rede municipal de ensino do Recife. 2009. 388 f. Dissertação (Mestrado em Educação) - Universidade Federal de Pernambuco, Recife, 2009.

MACHADO, L. B.; ANICETO, R. de A. Núcleo central e periferia das representações sociais de ciclos de aprendizagem entre professores. Ensaio: Avaliação e Políticas Públicas em Educação, Rio de Janeiro, v. 18, n. 67 , p. 345-363, abr./jun. 2010. DOI: 10.1590/S010440362010000200009

MADEIRA, M. C. Representações sociais: pressupostos e implicações. Revista Brasileira de Estudos Pedagógicos, Brasília, v. 72, n. 171, p. 129-144, maio/ ago. 1991.

Representações Sociais e Educação: importância teórico-metodológica de uma relação. In: MOREIRA, A. S. P.; JESUÍNO, J. C. (Orgs.). Representações sociais: teoria e prática. 2. ed. João Pessoa: EdUFPB, 2003. p. 113-133.
MAGALHÃES, L. M. Representações sociais da leitura: práticas discursivas do professor em formação. 2005. 194 f. Tese (Doutorado em Linguística Aplicada) - Universidade Estadual de Campinas, Campinas, 2005.

MANGUEL, A. Uma história da leitura. Tradução de Pedro Maia Soares. 2. ed. São Paulo: Companhia das Letras, 1997.

MARINHO, M. O discurso da ciência e da divulgação em orientações curriculares de língua portuguesa. Revista Brasileira de Educação, São Paulo, n. 24, p. 126-139, set./dez. 2003. DOI: 10.1590/S141324782003000300010

Inovações no ensino da língua portuguesa, no Brasil: elementos para uma análise discursiva de currículos. In: COLÓQUIO SOBRE QUESTÕES CURRICULARES, 7.; COLÓQUIOLUSO-BRASILEIRO, 3., Braga, 2006. Actas... Braga: EdUMinho, 2006. p. 828- 841 .

Currículos da escola brasileira: elementos para uma análise discursiva. Revista Portuguesa de Educação, Lisboa, v. 20, n. 1, p. 163-189, jan. 2007.

MENANDRO, M. C. S.; SOUZA, L. G. S. O que é ser bom aluno? O que é parar de estudar? Representações sociais de estudantes do ensino médio. Revista de Educação Pública, Cuiabá, v. 19, n. 39, p. 75-94, jan./ abr. 2010.

MENIN, M. S. de S.; LIMA, C. M. A teoria das representações sociais nos estudos sobre representações de professores. Cadernos de Pesquisa, São Paulo, v. 39, n. 137, p. 549-476, maio/ ago. 2009. DOI: 10.1590/S0100-15742009000200011

MENIN, M. S. de S.; SHIMIZU. A. M. Educação e Representação Social: Tendências de Pesquisas na área - Período de 2000 a 2003. In: ___. (Org.). Experiência e representação social: questões teóricas e metodológicas. São Paulo: Casa do Psicólogo, 2005. p. 92-130.

MOLLIER, J. Y. A história do livro e da edição um observatório privilegiado do mundo mental dos homens do século XVIII ao século XX. Varia História, Belo Horizonte, v. 25, n. 42, p. 521-537, jul./dez. 2009. DOI: 10.1590/S0104-87752009000200008

MOREIRA, A. S. P.; OlIVEIRA, D. C. de. (Orgs.). Estudos interdisciplinares de representação social. 2. ed. Goiânia: AB, 2000. p. 27-38.

MOSCOVICI, S. A representação social da psicanálise. Tradução de Álvaro Cabral. Rio de Janeiro: Zahar, 1978.

. Das representações coletivas às representações sociais. In: JODELET, D. As representações sociais. Tradução de Lilian Ulup. Rio de Janeiro: EdUERJ, 2001. p. 45-66.

Pourquoi l'étude des représentations sociales em psychologie? Psychologie et Société, v. 4, p. 7-24, 2002. 
Representações sociais: investigações em psicologia social. Tradução de Pedrinho Arcides Guareschi da versão inglesa publicada em 2000. 7. ed. Petrópolis: Vozes, 2010.

MUSIS, C. R. de; CARVALHO, S. P. de. Representações sociais de professores acerca do aluno com deficiência: a prática educacional e o ideal do ajuste à normalidade. Educação \& Sociedade, São Paulo, v. 31, n. 110, p. 201-217, jan./mar. 2010. DOI: 10.1590/S010173302010000100011

NÓVOA, A. Os professores e as histórias da sua vida. In: Vidas de professores. Porto: PortoEd, 1992. p. 11-17.

À escola o que é da escola. Entrevista concedida à Revista Gestão Escolar, jul. 2010. Disponível em: <http://revistaescola.abril.com.br/ gestao-escolar/diretor/antonio-novoa-fala-conteudosdevem-ser-prioritarios-escola-574267.shtml>. Acesso em: 15 jan. 2011.

OLIVEIRA, D. C. de; MARQUES, S. C.; GOMES, A. M. T.; TEIXEIRA, M. C. T. Análise das evocações livre: uma técnica de análise estrutural das representações sociais. In: MOREIRA, A. S. P. et al. (Orgs.). Perspectivas teórico-metodológicas em representações sociais. João Pessoa: EdUFPB, 2005. p. 573-603.

PASEYRO, R. Elogio do analfabetismo: ensaio sobre a incultura letrada ou de como foi usurpado o lugar dos depositários do verdadeiro saber. Tradução de Paulo Ramos. Lisboa: Mem Martins, 1990.

PEREIRA, A. P. S. S. Das representações sociais e das construções dos alunos acerca dos professores. Psicologia Educação e Cultura, Carvalhos, n. 1, p. 87-110, 1997.

PULLIN, E. M. M. P. A opção por um currículo disciplinar para a educação básica nas diretrizes curriculares do estado do Paraná: razões e estratégias enunciativas. In: COLÓQUIO SOBRE QUESTÕES CURRICULARES, 9.; COLÓQUIO LUSO-BRASILEIRO, 5., Porto, 2010. Anais... Porto, 2010a. p. 2344-2354.

PULLIN, E. M. M. P.; MOREIRA, L. de S. G. Prescrição de leitura na escola e formação de leitores. Ciências e Cognição, Rio de Janeiro, v. 13, n. 3, p. 231-242, nov. 2008.

ROCKWELL, E. La lecture scolaire comme pratique culturelle: concepts pour l'étude de l'usage des manuels. Éducation et Sociétés, n. 17, p. 29-48, 2006.

ROJO, R. (Org.). A prática de linguagem em sala de aula: praticando os PCNs. São Paulo: EDUC; Campinas: Mercado de Letras, 2000.

SÁ, C. P. de. Sur les relations entre representations sociales, pratiques socio-culturelles et comportement. Papers on social representations, Linz, Áustria, v. 3, n. 1, p. 40-46, 1994.
A construção do objeto de pesquisa em representações sociais. Rio de Janeiro: EdUERJ, 1998.

SANTOS, M. de F. de S.; ALMEIDA, L. M. de. (Org.). Diálogos com a teoria das representações sociais. Maceió: EdUFPE, 2005.

SAVELI, E. L. Leitura na escola: as representações e práticas de professoras. 2001. 174 f. Tese. (Doutorado em Educação) - Universidade Estadual de Campinas, Campinas, 2001.

SCHULZE, C. M. N. As representações sociais de pacientes portadores de câncer. In: SPINK, M. J. (Org.). O conhecimento no cotidiano: as representações sociais na perspectiva da psicologia social. São Paulo: Brasiliense, 1995. p. 266-279.

SILVA, E. T. da. Concepções de leitura e suas consequências no ensino. Perspectiva, Florianópolis, v. 17, n. 31 , p. 11-20, jan./jun. 1999a.

Leitura, cidadania e interdisciplinaridade. In: _. De olhos abertos: reflexões sobre o desenvolvimento da leitura no Brasil. 2. ed. São Paulo: Ática, 1999b. p.20-33.

SOARES, C. Em torno do pensamento social e do conhecimento do senso comum. A aplicação da metodologia alceste em contextos discursivos distintos. In: MOREIRA, A. S. P.; CAMARGO, B. V.; JESUÍNO, J. C.; NÓBREGA, S. M. (Orgs.). Perspectivas teóricometodológicas em representações sociais. João Pessoa: Editora Universitária UFPB, 2005. p. 541-571.

SOUZA, C. P. de. Develando la cultura escolar. In: JODELET, D.; TAPIA, A. do G. (Orgs.). Develando la cultura. México: Edunam, 2000. p. 127-151.

Estudos de representações sociais em educação. Psicologia da Educação: Revista de Estudos pós-graduados em Psicologia da Educação, São Paulo, v. 14/15, p. 285-323, jan./dez. 2002.

SPINK, M. J. (Org.). O conhecimento no cotidiano: as representações sociais na perspectiva da psicologia social. 2. ed. São Paulo: Brasiliense, 1995.

TEDESCO, J. C. Los desafíos de la educación básica en el siglo XXI. Revista Iberoamericana de Educación, Madrid, n. 55, p. 31-47, 2011.

TRAVERSINI, C. S.; BUAES, C. S. Como discursos dominantes nos espaços da educação atravessam práticas docentes? Revista Portuguesa de Educação, v. 22, n. 2, p. 141-158, 2009.

VERGĖS, P. Ensembles de programmes permettant l'analyse des evoctions: manuel version 2. Aix-enProvence: LAMES, 1999. 
. Os questionários para análise das representações sociais. In: MOREIRA, A. S. P. de; CAMARGO, B. V.; JESUÍNO, J. C.; NÓBREGA, S. M. (Orgs.). Perspectivas teórico-metodológicas em representações sociais. João Pessoa: EdUFPB, 2005. p. 201-228.

Recebido em 11/04/2011

Versão final recebida em 24/08/2011

Aceito em 10/10/2011 